\title{
Clobal Non-Profit Chains and the Challenges of Development Aid Contracting
}

\author{
${ }^{1}$ Department of Economics, Stellenbosch University, Stellenbosch, South Africa, E-mail: rburger@sun.ac.za \\ ${ }^{2}$ Nottingham University, Nottingham, UK, E-mail: trudy.owens@nottingham.ac.uk \\ ${ }^{3}$ Political Science, University of Washington Seattle, Seattle, USA, E-mail: aseem@u.washington.edu
}

\begin{abstract}
:
This paper employs Oliver Williamson's transaction cost approach to assess contracting. We find that donor contracting with global non-profit chains is conducive to NPO opportunism due to the asset specificity of the contracts, infrequent contracting, and the uncertainty of outcomes. These risks are further exacerbated by the weak enforcement mechanisms available in many developing countries. Williamson's framework predicts that these risks would tempt donors to resort to the muscular approach, where they would exercise maximum control over the non-profit chain. Although competition would be a safeguard against the muscular approach, the donor landscape suffers from collusion and is monopsonistic. Our analysis suggests that while the current contracting and oversight arrangements might serve the donor procedural objective to exercise control in a sector marked by information asymmetries, these arrangements can undermine the primary objective of donors, namely responsiveness to beneficiaries, and ultimately, improved beneficiary welfare. We illustrate our conceptual analysis with short case studies of three Ugandan NPOs.
\end{abstract}

Keywords: foreign aid, transaction costs, non-profits, aid chains, development

DOI: $10.1515 / \mathrm{npf}-2018-0026$

\section{Introduction}

Aid is an important source of governmental budgets and NPO funding for developing countries with limited tax income, often constituting a large share of their funding for education, health and other public interventions. Since the 1960s, aid flowing from developed to developing countries has increased steadily, rising in real terms from $\$ 36$ billion in 1960 to $\$ 58$ billion in 1980, to $\$ 72$ billion in 2010 and $\$ 144$ billion in 2017 (Organisation for Economic Co-operation and Development Development Finance Data 2017). ${ }^{1}$ According to the OECD's Development Assistance Committee (2018), $15 \%$ of bilateral official development aid was allocated to and through the non-profit sector in 2016. The 2017 Global Humanitarian Assistance Report (Development Initiatives 2017) notes that the non-profit sector directly received $37 \%$ of the humanitarian aid funding. ${ }^{2}$

Global non-profit chains (Silk 2004; Bebbington 2004; Wallace, Bornstein, and Chapman 2007; Pettit and Beresford 2009; Aveling 2010) have emerged in response to this increasing demand for NPO delivery of aid. Such chains can be configured in various ways. Here we consider a three-level hierarchy: (1) bilateral government and multilateral aid donors enter into a contract with an international NPO, (2) which subcontracts a local, predominantly urban, national NPO, which in turn, (3) subcontracts a local, often rural and more informal community NPO. We examine the oversight challenges from the initial contracting between the large donor and international NPO, and the subsequent subcontracting that various layers of NPOs undertake to fulfil the original contract.

To assess the merits and pitfalls of contracting between donors and international NPOs and subcontracting between international NPOs and other NPOs, we use Oliver Williamson's transaction cost framework. According to Williamson (1986, 1996, and 2008), contracting will be used if it is expected to reduce costs or yield greater benefits - inclusive of transaction costs. Donors choose to contract to reduce costs and harness local knowledge, expertise and relationships. They argue that contracting relegates the delivery of aid to organizations that have lower overheads, understand the beneficiary community and have established local reputations and trust relationships.

However, donor contracting relationships are marked by uncertainty, asset specificity and infrequent contracting. Williamson has demonstrated that in such contracting relationships, there will be a temptation to resort to a muscular approach - and in monopsonistic and collusive donor markets there will be little safeguard to 
protect NPOs against such behaviour. The muscular approach is exploitative and aims to exert maximum control over the NPO contractor, which in turn, inhibits the NPO's ability to adapt to changing local circumstances and be responsive to community needs. Given that responsiveness and adaptation are core to development goals, this is counterproductive and will impede the interests and goals of the donor.

In addition to the conceptual contributions laid out in the following section, we illustrate our argument by examining the subcontracting experiences of three Ugandan NPOs with long-standing donor relationships. We document the relevant insights from three instructive interviews with these NPOs and relate the cases back to our analytical framework and conclude with a discussion and a call for more research on this topic.

\section{Systemic Perspective on Clobal Non-Profit Chains}

In this section we look first at the politico-economic factors that led to the rise of global non-profit chains. We then explain the transaction cost approach to donor outsourcing. We end this section with an overview of three risk factors in donor subcontracting, particularly when the NPO uses a top-down muscular approach that can produce adverse development outcomes.

\subsection{The Political Economy of Clobal Non-Profit Chains}

Initially, donor aid was largely allocated to governments. However, concerns emerged the aid was not effective in promoting economic development (e. g. Burnside and Dollar 2000; Easterly 2010; Riddell 2008). The argument was that recipient governments' bureaucracies often did not have the knowledge, capabilities and incentives to identify the right beneficiaries to receive aid (Gibson et al. 2005). It was claimed that aid allowed some recipient governments to pursue projects that benefited their political supporters and not the most deserving (Lim, Mosley, and Prakash 2015). Aid diversion, corruption and the capture of the aid machinery by local elites compounded the problem.

Besides the ideology favouring civil society, donors also thought NPOs would make aid delivery more efficient. Attributing both virtue and competence to international NPOs, donors began to see them as the preferred vehicle to deliver aid abroad. In particular, donors made the assumption that international NPOs would be in a better position to identify local partner NPOs to carry out specific tasks and at the same time, be able to maintain paper trails to document prudential management.

This choice of aid delivery method coincided with an interest in the role civil society played in fostering economic development and democracy (Putnam 1995; Salamon 1994). Scholars saw international NPOs as the solution to the "twin failures" of the market and the state (Weisbrod 1988), romanticizing them as motivated to do good (Keck and Sikkink 1998) because the non-distribution constraint removes the incentive for opportunistic behaviour (Hansmann 1980).

There is however also an alternative perspective on the rationale for the emergence of NPOs. According to the transaction cost perspective, NPOs exist to reduce the cost of searching for, processing and communicating information (Valentinov 2008). Part of this argument hinges on the usefulness of the non-profit signal as a way to economize on search costs and connect organizations that are mission driven (and not prioritizing profit). In the case of developed country donors that seek to enhance the welfare of needy communities in developing countries, search costs may often be prohibitively expensive for outsiders. National NPOs and community NPOs with in-country knowledge and credibility make gaining such knowledge feasible. Additionally, close relationships with the community ensure that local NPOs can be more responsive to needs and can more easily adapt to changes in circumstances, which are at the heart of the development (Edwards and Hulme 1996).

A further response to the increased emphasis on aid effectiveness, and especially donor coordination and improved monitoring and evaluation, has been to lead donors to decrease the number of grants while increasing their average size. This has increased the demand for intermediation, generating consortiums and larger bureaucratic NPO intermediaries that have the capacity to manage the larger grants and comply with demands for better monitoring and evaluation, thus spawning non-profit chains. These non-profit chains are analogous to the for-profit supply chains (Cohen and Mallik 1997; Oloruntoba and Gray 2006) or commodity chains (Gereffi, Humphrey, and Sturgeon 2005) used for commercial purposes by multinational corporations. The national NPOs are the critical link in these chains, between the international NPOs who receive the funding from donors, and the community NPOs who are "street-level bureaucrats" delivering aid (Lipsky 1971). National NPOs are typically urban, often well connected with government officials, and staffed by professionals with strong international networks (Fafchamps and Owens 2009); while community NPOs tend to be informal organizations with deep knowledge of the local community but lacking the bureaucratic skills and networks typically possessed by the staff of the national NPOs . 


\subsection{The Transaction Cost Approach to Contracting}

Williamson's (2008) transaction cost approach offers important insights in understanding the governance and organization of the NPO aid chains. It sheds light on the motivations of donors to contract out aid delivery, along with accountability challenges they face in such contracting relationships. Finally, it allows us to explore Williamson's approach in the broader context of resource dependency, uncertainty, monopsonistic donor markets, and information asymmetries between international and local actors in the organization of the aid delivery infrastructure.

Coase (1937) is credited with introducing the notion of transaction costs. He notes that firms incur costs in exchanges and contracts, specifically costs for finding, negotiating, and enforcing exchanges and contracts. In the Coasian perspective, firms arise to economize on such costs: the higher the transaction costs of an activity, the more likely it will be that the firm will expand so that this activity can take place within the firm, rather than via exchange or contracts with external providers.

According to Williamson the transaction costs approach differs from neoclassical economics because it makes allowances for "human nature as we know it" (1981). In short, this entails acknowledging that we make mistakes and that we are capable of dishonest and opportunistic behaviour. Acknowledging that we make mistakes can also be described as decision making under bounded rationality, i. e. that we do not always make the best possible choices due to cognitive and time limits. In turn, acknowledging that we are capable of dishonest, opportunistic behaviour means that institutional and contract design are important, because they need to safeguard against exploitative and opportunistic behaviour.

Williamson views contracting as the "canonical transaction for transaction cost economics" $(2008,5)$. Williamson (1986) describes the conditions that would encourage organizations to transact and contract but, at the same time, the conditions that would make contracting challenging and would raise transaction costs. Transaction costs associated with contracting can be substantial, especially because many of these costs are not one-off, but ongoing.

With these costs in mind, Williamson (1986) argues that any organization responsible for delivering a good or service faces the make-or-buy decision. The organization can either produce the inputs and assemble them itself or buy these activities from external organizations. The make decision is represented by what he calls the hierarchy, which is the expansive firm, that has opted for in-house production. At the other extreme is the market, where goods and services are exchanged freely with no contracts required. Due to high-powered incentives, less need for administrative control, and the fact that parties can rely on the rule of law to settle disputes, markets are associated with lowered transaction costs. By contrast, the make option and the hierarchy implies a greater degree of administrative control, weaker incentives and internal dispute resolution mechanisms. Contracting is considered a hybrid between the market and the hierarchy and pursued when transaction costs favour buying but risks for opportunism requires additional safeguards.

Donors face the same make-or-buy decision when planning their development aid budgets. Donors want to improve the lives of beneficiaries in developing countries but need to choose whether they want to be directly involved or not. If they are directly involved - and make or execute these projects themselves - they will have substantial control. However, they will also incur high transaction costs because donors seldom have the local knowledge, expertise or relationships required to initiate and run development projects to help beneficiaries in developing countries. To effectively improve beneficiary welfare it is vital to understand the context and be responsive to local need. Donors are unlikely to have the on-the-ground presence and relationships of trust to do this well. In most cases they will thus choose to lower transaction costs by contracting national and local NPOs to help them deliver aid to beneficiaries. ${ }^{3}$

In the context of outsourcing to non-profit chains, it is however important to note that there are significant risk factors that can tempt the suppliers (in this case the subcontracted NPOs) into opportunistic behaviour: either to renege on the agreement for one's own gain, for instance not delivering on aspects of the contract that are difficult to monitor or enforce; delivering late; or, if it is possible to get away with it, not delivering the contracted goods and services at all. This makes subcontracting more risky and more challenging. Opportunistic behaviour is more likely when transactions are infrequent, when the contracted asset is specific to the contract and when there is uncertainty in the measurement and the production of outcomes. Each of these are explained in turn below - in the context of subcontracting with non-profit chains.

In donor aid chains, transactions are infrequent because donor contracts tend to run over two to five years and most NPOs have only one or a few donors (Aldashev and Navarra 2018). In thicker markets, the threat of losing future contracts due to opportunistic behaviour would serve as an effective deterrent to inhibit opportunistic behaviour, but due to the low number of concurrent donor contracts and the time lapses between donor decisions there is limited scope for reputation effects to safeguard against opportunism.

Aid subcontracting is asset-specific due to the importance of relationships and the insistence of donors on each having their own reporting templates and categories. Investments of the donor's staff time in building rapport and teaching NPO staff how to use their reporting categories and templates cannot be easily redeployed 
in future contracts and will be lost if the contract is ended. ${ }^{4}$ Relatively short contracting periods for ambitious community-level deliverables (often three to five years) and tight deadlines for the disbursements of funds further add to this "hold-up" threat.

Development outcomes from donor aid are uncertain due to their complexity and open-ended nature. In most cases their ultimate aim is to improve human knowledge, attitudes or behaviour, which are often difficult to measure reliably. Furthermore, the political and social environment is often not stable which introduces further variability making contracting particularly challenging. This complexity and murkiness make it difficult for a third party to evaluate an NPO's effort and performance. The implication of this asymmetric information problem is that contracts cannot be used to effectively encourage effort and reward performance, thus inviting opportunistic behaviour.

This uncertainty is further exacerbated because institutional protection against opportunism (such as corruption, siphoning or misuse of aid funds) is often weak or absent in developing countries. Rule of law is often lax and sector-specific oversight and regulatory mechanisms, such as non-profit peer monitoring and government regulation, are inadequate to prevent or punish opportunistic behaviour.

Many scholars suggest that NPOs are different because they attract altruistic staff, and that this means that opportunism is less of a threat. However, there is little empirical basis for this article of faith. We recognize that there is some support for the donative labour hypothesis and altruistic self-selection into the non-profit sector in developed countries (e.g. Jones 2015; Leete 2001). However, there are no empirical studies examining this hypothesis in developing countries where unemployment is high and there are low entry barriers for starting a NPO. Often the primary motive for seeking employment in an NPO or starting an NPO is financial necessity, not altruism. Lucrative aid funding contracts and low entry barriers to the non-profit sector could lure many entrepreneurs into the sector - especially given high levels of unemployment. Ahmad (2007) reports that in Bangladesh most community NPOs employ individuals whose first preference was to secure a government job. If we cannot assume altruism, donors have legitimate concerns that NPOs could behave opportunistically.

Concerns about NPO opportunism are not unfounded. In developing countries the media frequently expose scandals involving corrupt and ineffective NPOs, demonstrating that concerns about opportunistic behaviour are real (Prakash and Gugerty 2010). There are widespread references in the literature to "briefcase NPOs" (i. e. run from the manager's briefcase), which have no physical presence in the community, little commitment to the community and are concerned only to procure funding. However, their shadowy existence makes it difficult to estimate their prevalence accurately. Barr et al. (2005) could locate only one in four registered NPOs - even after a considerable investment in tracking Kampala-based NPOs, including phone calls and visits to the physical addresses provided at registration. They concluded that many of those they could not locate were briefcase NPOs.

To address the risk of opportunism donors can behave in one of three ways when they are subcontracting NPOs. Williamson identifies the benign buyer who he describes as naive in assuming suppliers will not behave strategically and thus do not safeguard themselves against opportunistic behaviour. Williamson regards the benign approach as suboptimal. At the opposite pole are the over-strategic muscular buyers, who are more powerful than the suppliers and can thus exploit them. Williamson $(2008,10)$ says buyers of this kind have a "peremptory" manner and "use up their suppliers and then discard them". Buyers of this kind fully specify the features of the products they want and the suppliers merely deliver. Taking a top-down approach, muscular buyers may adopt many of the worst features of hierarchical governance, but with few of the institutional safeguards, thus often failing to adapt to changes in circumstances and in clients' needs. Competition amongst buyers is the best safeguard against exploitation by muscular buyers. Williamson recommends the middle way of the credible buyer, one who behaves cooperatively but is also careful to discourage opportunistic behaviour, for instance by using verification mechanisms or applying penalties for premature termination.

\subsection{The "Muscular" Approach to Donor Contracting and Subcontracting}

Given the institutional context described above, we would expect donors to resort often to muscular outsourcing with non-profit chains. According to the Williamson framework, competition between donors would discourage the emergence of muscular subcontracting. However, Koch et al. (2009), Easterly (2010) and Frot and Santiso (2011) provide evidence of donor collusion and "herding", which strengthens the donors' position vis-à-vis the NPOs they subcontract creating a monopsonistic donor landscape. Frey (2008) suggests that one of the reasons why there is little competition between international organizations such as the World Bank and the UN is that their government mandate prohibits other entrants - and most other donor organizations are similarly constrained. In addition to enabling muscular contracting, collusion ${ }^{5}$ and monopsony also discourage diversity, innovation and responsiveness. By contrast, there has always been an oversupply of NPO contractors and the situation has probably been worsened by the recent rapid increase in the numbers of international and local NPOs (Werker and Ahmed 2008). 
Recent empirical studies provide some evidence of the muscular approach anticipated by Williamson under these conditions. There is some tentative evidence that suggests donors often tend to behave strategically and in their own self-interest when allocating aid across countries (Alesina and Dollar 2000; Berthélemy 2006), but there is also evidence of cooperative and altruistic behaviour amongst a subset of donors (Berthélemy 2006; Nunnenkamp and Ohler 2011). These interpretations are, however, contentious and it is not clear whether it is prudent to make inferences about donor subcontracting behaviour on the basis of donor decisions on aid allocation.

However, the lack of donor transparency on outsourcing makes it difficult to assess the prevalence of muscular donor contracting, but the observed adverse consequences of donor contracting may lead us to infer its presence. Burger and Owens (2013), for instance, show that many Ugandan NPOs have never received donor funding and, being "outsiders", are unlikely to receive it in the future. They find that NPOs that receive better assessments from their beneficiaries are no more likely than their peers to be awarded donor funding. The broken feedback loops between donors and beneficiaries also means that even if transactions were more frequent, reputation would not be effective as a self-monitoring mechanism. Burger and Owens conclude that the allocation of donor funds appears to be driven by donor habit and the desire to perpetuate existing relationships, fostering a system of dependence and patronage.

As outlined earlier, donors typically contract with international NPOs, or an international consortium where international NPOs are in the lead position. These international NPOs then typically subcontract with countrylevel NPOs. These sorts of NPOs are most often professional, urban based, and speak the global aid language. Yet, national NPOs often do not have expertise in service delivery or relationships with the local rural communities (Barr and Fafchamps 2006; Fafchamps and Owens 2009). They tend to be bureaucratic, urban-based organizations and are unlikely to have local community offices or much direct contact with the community. Consequently, national NPOs need to subcontract the actual aid delivery to community NPOs ${ }^{6}$ who serve as the interface between the aid recipient and the global aid chain.

Muscular contracting means that donors impose substantial reporting requirements on NPOs. But this reporting burden associated with strong administrative control and a muscular approach to subcontracting has also been blamed for the weakened accountability and responsiveness of the subcontracted NPOs. Ebrahim (2005) has called this "accountability myopia" because the donor's bureaucratic reporting requirements distract NPOs from their mission and oblige their staff to spend more time in the office and less time in the community.

Because community NPOs are funded by national NPOs, their priorities and their reporting burden are inevitably transmitted along the contracting chain to the community NPOs. Community NPOs are particularly vulnerable because they are at the end of the chain. Cohn et al. (2011) interviewed 2,910 individuals from health NPOs in Kenya, Malawi, Uganda and Zambia. They found that African non-profit health contractors were indignant and frustrated. They complained that funders had bypassed community NPOs with proven expertise and commitment in favour of briefcase NGOs with the required financial management, grant writing and monitoring and evaluation capacity, but no track record.

Muscular donor contracting with its emphasis on maximum control may also limit the scope for responding or adapting to the conditions or characteristics of the specific community. That this indeed happens can be seen in practice: the space for local NPOs to respond to the community tends to be limited because the (ultimate) contracts with the donors usually specify most of the project parameters. And when a delivery chain has many subcontractor links, feedback and accountability become considerably more complicated. Under such pressure, contractors and their subcontractors may become mere "ladles in the global soup kitchen" - as Fowler (1994) puts it.

The problems described above suggest that while the muscular donor approach emerges in response to specific contracting and institutional context, it may cause a misalignment that obstructs responsiveness of the aid provider to the client community. This is a serious concern. Responsiveness to the beneficiary community is recognized to be central to the ethics of development work. More generally, Williamson (2008) argues that the core function of organizations is to adapt and be responsive.

\section{Case Studies of Three Ugandan National Non-Profit Organizations}

Following Crowe's argument that case studies provide "an in-depth appreciation [of an issue] in its natural, real-life context" (Crowe et al. 2011, e1), in this section we provide evidence of the subcontracting experiences of three Ugandan NPOs with long-standing donor relationships. The aim is to use the case studies to study the challenges of subcontracting in practice and understand whether the proposed analytical framework provides a useful lens to interpret these experiences. ${ }^{7}$ 
There are at least three motivations in support of selecting illustrative NPO case studies from Uganda. Firstly, Uganda has had an extended and intensive history of donor funding and contracting, often described as the donor poster child. ${ }^{8}$ They eventually lost favour with donors due to their political troubles and also scandals surrounding the misuse of donor funds, with many organizations left to navigate difficult or challenging subcontracting and funding situations. Secondly, in an era where donors are moving away from middle-income countries and regions experiencing growth (Pallas, Anderson, and Sidel 2018) it is appropriate to select case studies from a low-income African country, where aid is set to remain an important contributor to social development and poverty alleviation. Lastly, Uganda's NPO sector is well-researched there is more context to interpret and validate the experiences described in the case studies.

The selected short instructive case studies include a leading national NPO for the disabled, a national NPO for community empowerment, and an HIV health services national NPO. We received notes and the audios from the three interviews and used these sources to document the experiences of the NPOs. To protect the anonymity of the NPOs and their funders, we have not included the names of the contracting parties.

The aim of these real-life snippets is to consider whether we see evidence of the perils Williamson anticipated when contracting happens amidst uncertain circumstances, power imbalances and with infrequent transactions.

\subsection{A Leading NPO for the Disabled}

In 1987 a group of people with disabilities formed an organization to help the disabled. The founders received seed money from a large European NPO. This international NPO has been their partner for 26 years. However, despite this particularly strong and long-lasting partnership, the NPO's story is one of continually applying for funding. In their own words, it is a case of "apply, apply, apply". They are funded predominantly by European disability NPOs and mostly receive small grants for specific projects. All the funding comes with a commitment to produce reports which they take very seriously as they understand the importance of the reports for determining their future funding chances. They say the demand for projects is driven by beneficiaries: they talk about responding to adverts, watching the press for funding calls and continually writing proposals.

Their fluctuating funding means they have to subcontract. With precarious revenue sources, they cannot employ a permanent body of staff and instead have to employ individuals and community NPOs to implement their projects. This affects their performance. They are continually training new people, which places considerable strain on their organization.

While they argue that their aim is to add value to their beneficiary community which they emphasize in their funding applications, they realistically admit that they need to comply with donor reporting to retain their jobs. In the interview, they mention reporting obligations far more frequently than delivering services to beneficiaries.

Although this NPO itself came from the beneficiary community, with its founders being themselves disabled, they mentioned the beneficiaries only in connection with donor requirements. They said that in the past they used to organize feedback meetings with beneficiaries, but with declining funds this has not been possible for the past three years.

\subsection{Community Empowerment NPO}

Since their inception this national community empowerment NPO and its community NPO partners have depended on the same religious international NPO for funding. In 2009 the community NPO partners amalgamated to form a national NPO. Before the umbrella national NPO was established, the community NPOs reported directly to the funder (religious international NPO), but they have been reporting to the national NPO since it was established, and the national NPO in turn reports to the funder. The national NPO has recently been awarded a UNICEF grant, but this will also be routed via the international NPO.

The national NPO's staff complain that they struggle to build a reputation in the sector because being part of this chain reduces their visibility. They have always been identified by the name of the international NPO that funds them and have never had their own separate identity. "The logo mentions the funder's name more prominently than the NPO's name so when the projects are run on the ground the beneficiaries associate this with the funder." Despite not seeing any of the reputational brand benefits directly, they recognise that the close association with the INPO means that they help to carry the responsibility for maintaining the reputation of the INPO: "We are aware that if we implement the UNICEF project grant poorly it will impact on the reputation of the INPO".

It appears that the community NPOs have limited decision space and negotiating power. They complain that the establishment of the NPO umbrella was not their idea, but they also say this should not have been 
a surprise because, even before the amalgamation, the constituting community NPOs were "owned" by the international NPO.

The strong hierarchical relationship and vertical integration are also evidenced by the secondment of international NPO staff, including the finance officer, to the offices of the NPO. An NPO staff member said: "Their staff is sitting here. We are an extension of them." The NPO complained that, despite the strong hierarchy and implied control, the international NPO does not want to cover the cost of their overheads and insists that the money it provides "should benefit children directly". The implication is that the NPO should raise money from the community to fund operational expenses such as maintaining its offices.

\subsection{An HIV Health Services NPO}

This Ugandan NGO has been supporting HIV health services in Uganda since 2004. Their main mission is to help fight HIV but they also provide reproductive health services. They have often worried about their organization's financial sustainability because they are entirely donor-funded and donors have cycles of funding. When a cycle comes to an end they have to re-apply and even if they have been with the donor for some time it is not guaranteed that they will get a grant. Even during a funding cycle, there have been project reviews where the government or funders changed their priorities on the basis of new data and then required the national NPO to change the focus of its projects. They said they had recently been obliged to reduce the number of districts in which they work from fourteen to seven, which reduced their revenues and led to staff retrenchments.

They mentioned a three-month period of severe cash flow constraints when the donor unexpectedly extended their project review period. This impeded project activities. The experience has motivated them to diversify their funding streams to protect themselves against an overreliance on their major donor. They have been worried about the situation for some time because they have noticed a decline in donor funding and a large increase in registered NPOs in their sector. They note that "competition is increasing in Uganda".

Due to the move to matched funding, they have found it challenging to procure additional funding.

Matched funding means that you can't get $100 \%$ of funding for a project from a single donor. But if you have money, then you find more money. Now, that has the challenge that often funding timelines may not align. You might get one grant for two years and yet it is being leveraged based on a one-year grant.

They complained about the high entry cost of procuring new grants, saying that because of the donors' networking "you cannot hide anything from them". They said they had little chance of getting funding from new sources, and that establishing and maintaining a reputation was essential for procuring donor funding. They complained about how difficult it is to get funding for initial investments in capacity and reputation and suggested that there should be more seed grants to help support NPOs that are trying to grow. They said

The donors do a lot of due diligence on internal processes ... No donor wants to give funding to an organisation that does not have the required oversight in place. The donor wants to see that the NPO has policies and structures to safeguard against the misallocation of funding.

When they were asked to explain how an NPO establishes a strong reputation, they did not mention value for communities or project deliverables, but instead pointed to observable measures of good governance such as having a well-functioning board of directors or board of trustees and three years of audited financial reports.

\section{4 "Muscular" Donors in Practice?}

As anticipated by Williamson's framework, the short instructive case studies illustrate that subcontracted NPOs have limited scope for taking initiative and being responsive to their client communities. National NPOs are preoccupied with meeting donor obligations and procuring funding. Admittedly, we would expect this diversion of focus from the real aim, i. e. helping the community, to be more severe for leadership than for project staff. The interviews were conducted with NPO leaders and managers, not with general staff. However, it remains a concern that funding occupies such a large share of the attention and energy of NPO leaders. There is a risk that this preoccupation could crowd out other leadership responsibilities such as human resource management and strategic responses to community feedback, which would affect the long-term viability and effectiveness of the organization.

Also, as anticipated by Williamson's framework, the three NPOs discussed above see donors as exerting tight control over them. The community empowerment NPO used strong terms such as "owned" and complained about having little separate identity or reputation. It appears to take on significant responsibility and 
risk to deliver projects and maintain the reputation of the international NPO, yet has little say in decisions made by the international NPO.

While these NPOs take initiatives to manage their financial risks, it is clear that they are reliant on the preferences of donors and that this severely constrains their decision making, with uncertainty and risk often being passed down the non-profit chain. The interviews showed that they find it difficult to recruit and retain staff when funding tends to cover direct project expenses only for the duration of the project. The disability NPO addressed this problem by relegating the risks even lower down the chain by subcontracting community NPOs. This may solve the NPO's problem, but it is unlikely that the community NPOs are able to manage the risks better than the NPO. Given their smaller size and more informal nature, they are probably even less well equipped to do so. Since the work of NPOs is reliant on their own experienced and knowledgeable staff, we highlight this as a key concern for the sector and recommend that further research be conducted on this question.

The interviews showed that the NPOs felt they had little power in their relationships with donors and had to follow the rules set by the donors. According to the HIV NPO, tight donor networks and intensified competition for funding have exacerbated the problem.

The interviews also highlighted the complexity and murkiness of measuring project impact and warned that organizational effectiveness may increase the tension between donor and community accountability and support the commodification of development projects. The HIV NPO identified "structures and policies" - and specifically three years of audited financial statements and a well-functioning board - as the most important requirements for procuring donor funding. When asked to explain how to establish a good reputation with the donors, interviewees referred to policies and processes and failed to mention their relationship with their beneficiary communities.

While these are only the perceptions of three national NPOs, they remain a valid concern because they are motivating the choices and priorities of these NPOs. These choices and priorities may be due to the evolving role of the NPO in the extended non-profit chains, with delivery and community relationships increasingly being relegated to the community NPO, but the concern is that because the national NPO is funding the community NPO it will transfer its priorities to the community NPO via its subcontracting, diverting the community NPO away from its work in the community, placing the focus on paperwork rather than people. The experiences outlined here often overlap with existing published case study evidence and this provides some support for the external validity of the concerns raised.

\section{Discussion and Conclusions}

In recent years donors have faced a heightened demand for accountability due to aid fatigue and the rising prominence of accountability on the global agenda with the Paris Declaration on Aid Effectiveness in 2005 and the Accra Agenda for Action in 2008. This prompted donors to provide more evidence of their effectiveness so as to justify and validate aid spending to local taxpayers. In turn, this has led to the emergence of extended global non-profit chains linking international NPOs, and their local partners, the national NPOs and their community NPO subcontractors. International NPOs and large, urban national NPOs have the capacity to meet these more stringent donor requirements in terms of oversight, monitoring and reporting. However, the national NPOs typically subcontract with community NPOs, thus making these smaller, local organizations responsible for the relationship with the beneficiary community and the fulfilment of the contract.

In this paper we contribute to the literature on intermediation and subcontracting of aid delivery both from a systemic perspective and from the vantage point of national NPOs which are links in such delivery chains. Due to the shortage of data and existing studies on this topic, we have opted to ground our approach in the analytical framework of Williamson (2008), supported by the available empirical literature. Due to the shortage of empirical literature, we also described the experiences of three donor-funded national NPOs in Uganda to illustrate the problems outlined in the theory framework.

We suggest that the identified weaknesses and problems of global non-profit chains are attributable to both the structure of the aid landscape and the nature of the relationships between organizations. Williamson's analytical framework suggests that uncertainty, infrequent transactions and asset specificity foster the risk of NPO opportunism, which is further enhanced by weak enforcement mechanisms in developing countries. A monopsonistic donor landscape allows donors to resort to muscular subcontracting. This is counterproductive because it restricts the NPO's ability to adapt and respond to the local community's changing needs which are at the centre of the donor's aims and goals and also the rationale for subcontracting non-profit chains.

Reforming the aid landscape to serve poor communities better has remained an elusive goal, perhaps partly because the current configuration of the donor landscape is presumed to be a given. The question of how to 
better govern the relationship between the donor and their non-profit chain has been a central concern in this paper. Although no doubt a radical option, more competition, more choice and greater transparency in the allocation decisions of development aid might promote more diverse, responsive and innovative development funding. Any attempts to increase competition would have to be considered in conjunction with solutions to the information asymmetry problem: more competition will not do any good unless it is driven by accurate, comparable and timely information on value added to communities.

Relationships between donors and NPOs could be improved by rethinking and redesigning the subcontracting system to promote a more equitable distribution of financial risks and more room for learning and continuous improvement. One proposal would be to consider deeper and longer-term collaborative partnerships amongst stakeholders (see for instance Levin (2003)'s proposal for "relational" contracts). Such collaborative arrangements would be governed by mutual trust, goodwill and reputation. Within the Williamson framework this can be viewed as a move away from subcontracting and towards hierarchy and integration. Under such an arrangement, there may be more scope for client responsiveness and a recognition of the complexity of sustained and long-term improvements in the lives of beneficiaries, which could make NPOs more willing to be fully transparent and share their on-the-ground experiences more honestly - including their failures - with peers and funders. There are examples of experiments with this model (e. g. the Forum for Educational NGOs in Uganda) but no robust research evidence as far as we know.

To address the information asymmetry problems described here, it is important to establish feedback links between donors and beneficiary communities. Donors typically rely on project feedback from the national NPO, a method that has limitations because the NPO has an incentive to describe the project as a success, to boost its reputation and increase the likelihood of continued funding. Cooley and Run $(2002,15)$ have argued that the danger of asymmetry in practice is that "if the project is not going according to the donor's plan, contractors or recipients - or possibly both - may conceal, withhold, or distort information harmful to their interests". Donors need to establish direct feedback links with beneficiary communities. The rapid spread of mobile phones throughout developing countries could ensure that direct communication channels between donors and beneficiary communities are feasible and cost-effective. Such feedback could have the added benefit of providing avenues to structure incentives to redirect the focus of national NPOs and community NPOs back to the beneficiary communities.

The interviews with three Ugandan national NPOs identified the difficulty of recruiting and retaining qualified, experienced staff members when funding is fluctuating as a key concern that requires further research and more discussion - particularly also because the staff are central to development projects and continuity is crucial for community relationships. This appears to be a symptom of a more fundamental problem: muscular subcontracting within non-profit chains manages uncertainty and risk by sending it down the chain, with much of it ending up at the lowest level where organizations are often poorly equipped to absorb and manage this risk. This can result in instability in the chain's community interface, which can be counterproductive given that this relationship is core to the rationale for contracting and crucial for ensuring that development aid is humane, responsive and effective.

\section{Notes}

1 These estimates are expressed in 2016 prices and have been derived using 2016 exchange rates. Note that aid flows are complicated because of the long subcontracting chains and complex routing, and differences in accounting practices make it difficult to compare estimates. Aid channelled to governments but redirected to NPOs will frequently not be counted as aid funding received by NPOs.

2 Note however that Appe and Pallas (2018) and Pallas, Anderson, and Sidel (2018) show that while aid is increasing on the whole, there are a number of countries that have experienced consistent declines in aid, often as they become more wealthy and acquire middle income status.

3 There are exceptions. Humanitarian aid NPOs often opt to "make" the outcomes themselves, delivering aid directly due to the urgency of the situation.

4 A similar point is made in the resource based view of the firm (Wernerfelt 1984), which is often suggested as an alternative to Williamson's transaction costs economics. Asset-specificity would imply that some depletion of resources created or gained during the contract, i. e. that they will not become part of the firm's semi-permanent resource base.

5 Collusion is not coordination: donor coordination would avoid duplication and promote specialisation, whereas collusion implies duplication and a narrower service offering, with donors imitating each other rather than acting as autonomous agents.

6 With cross-sectional data, it is of course not possible to separate cause and effect, i. e. to decide whether the weaknesses of the national NPOs were caused by their practice of subcontracting to community NPOs or whether they were pre-existing weaknesses that necessitated the practice.

7 The examples were proposed by Dr Berta Silva from Stellenbosch University, the principal investigator of a larger qualitative study examining Ugandan NPO's financial sustainability and coping strategies amidst financial fluctuations. The examples were chosen to be representative of NPOs who are in subcontracting arrangements, and to ensure that there would also be some breadth in the description of experiences, the NPOs were selected from different subsectors. The three interviews were conducted on March 14, 2016, August 31, 2016 and August 9, 2016 (dates listed in order that the interview appear). 
8 See for instance references to this in The Guardian https://www.theguardian.com/society/katineblog/2009/may/26/uganda-andpoverty and also Fox News http://www.foxnews.com/world/2018/02/14/major-refugee-aid-fraud-under-investigation-in-uganda-u-nreveals.html

\section{References}

AbouAssi, K. 2013. “Hands in the Pockets of Mercurial Donors: NPO Response to Shifting Funding Priorities.” Nonprofit and Voluntary Sector Quarterly 42: 584-602.

Agrawal, A., and C. Cibson. 1999. "Enchantment and Disenchantment: The Role of Community in Natural Resource Conservation." World Development 27: 629-49.

Ahmad, M. 2007. "The Careers of NGOs Field-Workers in Bangladesh." Nonprofit Management \& Leadership 17: 349-65.

Aldashev, G., and C. Navarra. 2018. “Development NCOs: Basic Facts." Annals of Public and Cooperative Economics 89 (1): 125-55.

Alesina, A., and D. Dollar. 2000. "Who Cives Aid to Whom and Why?" Journal of Economic Growth 5 (1): 33-63.

Appe, S., and C. Pallas. 2018. "Aid Reduction and Local Civil Society: Causes, Comparisons, and Consequences." VOLUNTAS: International Journal of Voluntary and Nonprofit Organizations 29 (2): 245-55.

Aschari-Lincoln, J., and U. Jäger. 2016. "Analysis of Determinants of Revenue Sources for International NCOs: Influence of Beneficiaries and Organizational Characteristics." Nonprofit and Voluntary Sector Quarterly 45: 612-29.

Aveling, E. L. 2010. “The Impact of Aid Chains: Relations of Dependence or Supportive Partnerships for Community-Led Responses to HIV/AIDS?" Aids Care 22 (sup2): 1588-97.

Barr, A., and M. Fafchamps. 2006. “A Client-Community Assessment of the NGO Sector in Uganda." The Journal of Development Studies 42 (4) 611-39.

Barr, A., M. Fafchamps, and T. Owens. 2005. “The Governance of Nongovernmental Organizations in Uganda." World Development 33: $657-79$. Bebbington, A. 2004. "NCOs and Uneven Development: Ceographies of Development Intervention." Progress in Human Geography 28 (6): $725-45$.

Berthélemy, J-C. 2006. “Bilateral Donors' Interest vs. Recipients' Development Motives in Aid Allocation: Do All Donors Behave the Same?" Review of Development Studies 10 (2): 179-94.

Bogart, W. T. 1995. “Accountability and Nonprofit Organizations: An Economic Perspective.” Nonprofit Management and Leadership 6 (2): 15770.

Burger, R., I. Dasgupta, and T. Owens. 2015. “Why Pay NCOs to Involve the Community?" Annals of Public and Cooperative Economics 5: 7-31.

Burger, R., and T. Owens. 2010. "Promoting Transparency in the NPO Sector: Examining the Availability and Reliability of Self-Reported Data." World Development 38: 1263-77.

Burger, R., and T. Owens. 2013. “Receive Grants or Perish? the Survival Prospects of Ugandan Non-Covernmental Organisations." Journal of Development Studies 49: 1284-98.

Burnside, C., and D. Dollar. 2000. “Aid, Policies, and Growth.” American Economic Review 90: 847-68.

Chahim, D., and A. Prakash. 2014. “NGOization, Foreign Funding, and Nicaraguan Civil Society." Voluntas 25: 487-513.

Coase, R. 1937. "The Nature of the Firm." Economica 4 (16): 386-405.

Cohen, M., and S. Mallik. 1997. "Clobal Supply Chains: Research and Applications." Production and Operations Management 6: 193-210.

Cohn, J., A. Russell, B. Baker, A. Kayongo, E. Wanjiku, and P. Davis. 2011. “Using Clobal Health Initiatives to Strengthen Health Systems: A Civil Society Perspective." Global Public Health 6 (7): 687-702.

Cooley, A., and J. Ron. 2002. "The NCO Scramble: Organizational Insecurity and the Political Economy of Transnational Action." International Security 27 (1): 5-39.

Crowe, S., K. Cresswell, A. Robertson, G. Huby, A. Avery, and A. Sheikh. 2011. “The Case Study Approach.” BMC Medical Research Methodology 11: 100. doi:http://www.biomedcentral.com/1471-2288/11/100.

Dalgaard, C., H. Hansen, and F. Tarp. 2004. “On the Empirics of Foreign Aid and Crowth.” The Economic Journal 11: F191-F216.

Development Assistance. 2017. Global Humanitarian Assistance Report 2017. Bristol: Development Assistance.

Development Assistance Committee. 2018. Aid for Civil Society Organisations: Statistics Based on DACMembers' Reporting to the Creditor Reporting System Database (CRS), 2015-2016. https://www.oecd.org/dac/financing-sustainable-development/development-finance-topics/Aid-forCivil-Society-Organisations-2015-2016.pdf.

Dupuy, K., and A. Prakash. 2018. “Do Donors Reduce Bilateral Aid to Countries with Restrictive NCO Laws?: A Panel Study, 1993-2012." Nonprofit and Voluntary Sector Quarterly 47 (1): 89-106.

Easterly, W. 2010. "The Cartel of Cood Intentions: The Problem of Bureaucracy in Foreign Aid." The Journal of Policy Reform 5 (4): 223-50.

Ebrahim, A. 2003. "Making Sense of Accountability: Conceptual Perspectives for Northern and Southern Nonprofits." Nonprofit Management and Leadership 14 (2): 191-212.

Ebrahim, A. 2005. “Accountability Myopia: Losing Sight of Organizational Learning." Nonprofit and Voluntary Sector Quarterly 34: 56-87.

Edwards, M., and D. Hulme. 1996. "Too Close for Comfort? the Impact of Official Aid on Nongovernmental Organizations." World Development 24: 961-73.

Etzioni, A. 1998. The New Colden Rule: Community and Morality in a Democratic Society. New York: Basic Books.

Fafchamps, M., and T. Owens. 2009. "The Determinants of Funding to Ugandan Nongovernmental Organizations." The World Bank Economic Review 23: 295-321.

Fowler, A. 1994. Capacity building and NCOs: A case of strengthening Ladles for the global soup kitchen. Institutional Development (Innovations in Civil Society) Vol. 1, no. 1. New Delhi, India: Society for Participatory Research in Asia. 18-24.

Frey, BS. 2008. “Outside and inside competition for international organizations-from analysis to innovations." The Review of International Organizations 3(4): 335-50. 
Frot, E., and J. Santiso. 2011. "Herding in Aid Allocation." Kyklos 64 (1): 54-74.

Cereffi, G., J. Humphrey, and T. Sturgeon. 2005. "The Governance of Global Value Chains." Review of International Political Economy 12: 78-104.

Cibson, C., K. Andersson, E. Ostrom, and S. Shivakumar. 2005. The Samaritan's Dilemma: The Political Economy of Development Aid. Oxford: Oxford University Press.

Giddens, A. 1998. The Third Way. Cambridge, UK: Polity Press.

Hammami, R. 1995. “NPOs: The Professionalization of Politics." Race and Class 37: 51-64.

Hansmann, H. B. 1980. “The Role of Nonprofit Enterprise." The Yale Law Journal 89 (5): 835-901.

Hyndman, N., and D. McConville. 2016. "Transparency in Reporting on Charities' Efficiency: A Framework for Analysis." Nonprofit and Voluntary Sector Quarterly 45: 844-65.

Jones, D. 2015. “The Supply and Demand of Motivated Labor: When Should We Expect to See Nonprofit Wage Gaps?.” Labour Economics 32: $1-14$.

Keck, M., and K. Sikkink. 1998. Activists beyond Borders. Ithaca, NY: Cornell University Press.

Kibreab, C. 2004. "Pulling the Wool over the Eyes of the Strangers: Refugee Deceit and Trickery in Institutionalized Settings." Journal of Refugee Studies 17: 1-26.

Kihika, M. 2009. “Development or Underdevelopment: The Case of Non-Governmental Organizations in Neoliberal sub-Saharan Africa." Journal of Alternative Perspectives in the Social Sciences 1: 783-95.

Kilby, P. 2006. "Accountability for Empowerment: Dilemmas Facing Non-Governmental Organizations." World Development 34: 951-63.

Koch, D-J., A. Dreher, P. Nunnenkamp, and R. Thiele. 2009. “Keeping a Low Profile: What Determines the Allocation of Aid by NonCovernmental Organizations?" World Development 37 (5): 902-18.

Kristoff, M., and L. Panarelli. 2010. Haiti: A Republic of NGOs? Peace Brief 23. Washington, DC: United States Institute of Peace.

Leete, L. 2001. "Whither the Nonprofit Wage Differential? Estimates from the 1990 Census." Journal of Labor Economics 19 (1): 136-70.

Levin, J. 2003. "Relational Incentive Contract." American Economic Review 93 (3): 835-57.

Lewis, D., and T. Wallace. 2000. New Roles and Relevance: Developmental NPOs and the Challenge of Change. Hartford, CT: Kumarian Press.

Lim, S., L. Mosley, and A. Prakash. 2015. "Revenue Substitution? How Foreign Aid Inflows Moderate the Effect of Bilateral Trade Pressures on Labor Rights." World Development 67: 295-309.

Lipsky, M. 1971. "Street-Level Bureaucracy and the Analysis of Urban Reform." Urban Affairs Quarterly 6 (4): 391-409.

Macdonald, L. 1997. Supporting Civil Society: The Political Role of Non-Covernmental Organizations in Central America. New York: St Martin's Press, Inc.

Mansuri, G., and V. Rao. 2013. Localizing Development: Does Participation Work? Policy Research Report. Washington, DC: World Bank.

Mitchell, G. E. 2014. “Strategic Responses to Resource Dependence among Transnational NGOs Registered in the United States." Voluntas: International Journal of Voluntary and Nonprofit Organizations 25 (1): 67-91.

Murtaza, N. 2012. "Putting the Lasts First: The Case for Community-Focused and Peer-Managed NPO Accountability Mechanisms." Voluntas 23: 109-25.

Nunnenkamp, P, and H. Ohler. 2011. “Aid Allocation through Various Official and Private Channels: Need, Merit and Self-Interest as Motives of German Donors. European Journal of Political Economy." World Development 39 (3): 308-23.

OECD. (Organisation for Economic Co-operation and Development). 2017. Development Finance Data. Paris: OECD.

Olken, B. 2007. “Monitoring Corruption: Evidence from a Field Experiment in Indonesia." Journal of Political Economy 115: 200-49.

Oloruntoba, R., and R. Gray. 2006. “Humanitarian Aid: An Agile Supply Chain?” Supply Chain Management: An International Journal 11 (2): $115-$ 20.

Pallas, C., Q. Anderson, and M. Sidel. 2018. “Defining the Scope of Aid Reduction and Its Challenges for Civil Society Organizations: Laying the Foundation for New Theory." VOLUNTAS: International Journal of Voluntary and Nonprofit Organizations 29 (2): 256-70.

Pettit, S., and A. Beresford. 2009. “Critical Success Factors in the Context of Humanitarian Aid Supply Chains." International Journal of Physical Distribution \& Logistics Management 39 (6): 450-68.

Pfeffer, J., and C. R. Salancik. 2003. The External Control of Organizations: A Resource Dependence Perspective. Stanford: Stanford University Press. Prakash, A., and M. K. Gugerty. 2010. “Trust but Verify? Voluntary Regulation Programs in the Nonprofit Sector." Regulation \& Governance 4: 22-47.

Putnam, R. 1995. “Bowling Alone: America's Declining Social Capital.” Journal of Democracy 6: 65-78.

Riddell, R. 2008. Does Foreign Aid Really Work? Princeton and Oxford: Oxford University Press.

Riddell, R., and M. Robinson. 1995. Nongovernmental Organizations and Rural Poverty Alleviation. Oxford: Clarendon Press.

Robinson, M., and S. Friedman. 2005. Civil society, democratisation and foreign aid in Africa. IDS discussion paper 383. Brighton, England: Institute of Development Studies.

Roodman, D. 2007. "The Anarchy of Numbers: Aid, Development, and Cross-Country Empirics." The World Bank Economic Review 21: $255-77$.

Sach, J. 2005. The End of Poverty. New York: Penguin Books.

Salamon, L. 1994. “The Rise of the Nonprofit Sector.” Foreign Affairs 73: 109-22.

Silk, John. 2004. “Caring at a Distance: Cift Theory, Aid Chains and Social Movements." Social \& Cultural Ceography 5 (2): 229-51.

Smith, S. R., and M. Lipsky. 1993. Nonprofits for Hire. Cambridge, MA: Harvard University Press.

Stiles, K. 2002. "International Support for NPOs in Bangladesh: Some Unintended Consequences." World Development 30: 835-46.

Sundstrom, L. 2006. Funding Civil Society: Foreign Assistance and NPO Development in Russia. Stanford, CA: Stanford University Press.

Tacon, R., G. Walters, and C. Cornforth. 2017. “Accountability in Nonprofit Governance: A Process-Based Study.” Nonprofit and Voluntary Sector Quarterly 46: 685-704.

Townsend, J., G. Porter, and E. Mawdsley. 2002. "The Role of the Transnational Community of Nongovernmental Organizations." Journal of International Development 14: 829-39.

Valentinov, V. 2008. “The Transaction Cost Theory of the Nonprofit Firm: Beyond Opportunism." Nonprofit and Voluntary Sector Quarterly 37 (1): 5-18. 
Wallace, T., L. Bornstein, and J. Chapman. 2007. The Aid Chain: Coercion and Commitment in Development NGOs. Bourton on Dunsmore: Practical Action Publishing.

Weisbrod, B. 1988. The Nonprofit Economy. Cambridge, MA: Harvard University Press.

Werker, E., and F. Ahmed. 2008. “What Do Nongovernmental Organizations Do?" Journal of Economic Perspectives 22: 73-92.

Wernerfelt, B. 1984. “A Resource-Based View of the Firm." Strategic Management Journal 5 (2): 171-80.

Willems, J., C. Waldner, Y. Dere, Y. Matsuo, and K. Högy. 2017. “The Role of Formal Third-Party Endorsements and Informal Self-Proclaiming Signals in Nonprofit Reputation Building." Nonprofit and Voluntary Sector Quarterly 46: 1092-105.

Williamson, O.E. 1981. "The Economics of Organization: The Transaction Cost Approach." American Journal of Sociology 87: 548-77. https://doi.org/10.1086/227496.

Williamson, O. 1986. Economic Institutions of Capitalism. New York: New York Free Press.

Williamson, O. 1996. Mechanisms of Covernance. Oxford: Oxford University Press.

Williamson, O. 2008. “Outsourcing: Transaction Cost Economics and Supply Chain Management." Journal of Supply Chain Management 44 (2): 5-16. 